\section{AB1370-HPR COMPARISON OF SLEEP, FATIGUE AND SEXUAL PARAMETERS OF RHEUMATIC DISEASES}

Fatma Birgül Kumbaroğlu' ${ }^{1}$, Gamze Arın ${ }^{1}$, Nur Banu Karaca ${ }^{1}$, Şule Apraş Bilgen², Edibe Ünal' ${ }^{1}{ }^{1}$ Hacettepe University Faculty of Physical Therapy and Rehabilitation, Ankara, Turkey, ${ }^{2}$ Hacettepe University Faculty of Medicine, Department of Rheumatology, Ankara, Turkey

Background: Chronic pain, sleep, and fatigue are common complaints in rheumatic disease (1). However, each rheumatic disease has different characteristics. So that it can be thought that individuals can be affected by different diseases in different ways (2).

Objectives: The aim of this study is to compare sleep, fatigue and sexual parameters in different rheumatic diseases.

Methods: Individuals diagnosed with Rheumatoid Arthritis (RA), Ankylosing Spondylitis (AS) and Fibromyalgia (FMS) who applied to the Rheumatology Department of the Medical Faculty of Hacettepe University were included in the study. After the demographic characteristics of the individuals were recorded; sexual function, sexual willingness, fatigue, and sleep features were assessed with 11th, 27th, 29th and 30th items of BETYBiopsychosocial Questionnaire (BETY-BQ) which is developed in rheumatic patients (3)

Results: 160 RA, 108 AS, and 131 FMS patients were included in the study. The scores of individuals on scales are shown in Table 1. There was no statistically significant difference among the three groups in terms of BMI ( $p>0.05$ ), while the mean age of RA patients was statistically different from the other two groups $(p<0.05)$. The sleep, fatigue and sexual parameters (sexual function, sexual willingness) were examined with Kruskal Wallis analysis. When analyzed in terms of differences according to RA, AS and FMS, the responses to sleep $(p=0.015)$ and sexual functioning $(p=0.003)$ were found different according to the diseases. However, there was no significant difference in the sexual willingness $(p=0.248)$ and fatigue $(p=0.708)$ related to the disease. Mann-Whitney $U$ test was performed to test the significance of a pairwise difference using Bonferroni correction to adjust for multiple comparisons revealed that the difference between the groups was due to RA patients (Table 2).

Abstract AB1370HPR Table 1. Comparison of three groups.

\begin{tabular}{lccc}
\hline & RA $(\mathbf{n}=\mathbf{1 6 0})$ & AS $(\mathbf{n}=\mathbf{1 0 8})$ & FMS $(\mathbf{n}=\mathbf{1 3 1})$ \\
\hline Age & $51.44 \pm 0.83$ & $41.75 \pm 1.19$ & $43.60 \pm 0.78$ \\
BMl & $28.65 \pm 0.88$ & $27.49 \pm 0.52$ & $28.64 \pm 1.59$ \\
Fatigue & $3.02 \pm 0.10$ & $3.09 \pm 0.10$ & $3.17 \pm 0.87$ \\
Sexual function & $1.20 \pm 0.11$ & $1.64 \pm 0.15$ & $1.75 \pm 0.13$ \\
Sexual willingness & $1.50 \pm 0.12$ & $1.72 \pm 0.15$ & $1.77 \pm 0.13$ \\
Sleep & $2.12 \pm 0.12$ & $2.42 \pm 0.15$ & $2.64 \pm 0.12$ \\
\hline
\end{tabular}

Abstract AB1370HPR Table 2. Mann-Whitney U test

\begin{tabular}{lcc}
\hline & $\mathrm{p}$ & $\mathrm{p}$ \\
\cline { 2 - 3 } & No:27 Sexual function & No:30 Sleep \\
\hline RA-AS & 0.019 & 0.124 \\
RA-FMS & 0.001 & $\mathbf{0 . 0 0 4}$ \\
AS-FMS & 0.528 & 0.278 \\
\hline
\end{tabular}

Conclusion: As a result, all the patients who participated in this study have sleep, fatigue and sexual problems. Although the mean age of RA patients is higher than other patients, it is quite interesting that they have less sleep and sexual function problems. On the other hand, it was expected that symptoms of RA and AS diseases due to their inflammatory nature would be worse than FMS. Moreover, it can be estimated that AS patients have spinal involvement and this situation may affect their sexual function, but FMS patients' results in terms of these parameters were unclear. It was concluded that the psychosocial characteristics were taken into consideration especially in FMS patients' sexual parameters, fatigue, and sleep features during the disease management.

\section{REFERENCES}

[1] Moldofsky, Harvey. "Rheumatic manifestations of sleep disorders." Current Opinion in Rheumatology 22.1 (2010): 59-63.

[2] Hurd, Kelle, and Cheryl Barnabe. "Systematic review of rheumatic disease phenotypes and outcomes in the Indigenous populations of Canada, the USA, Australia, and New Zealand." Rheumatology international 37.4 (2017): 503-521.

[3] Unal, Edibe, et al. "Effectiveness of a Biopsychosocial Exercise Approach in Rheumatic Diseases." Arthritıs \& Rheumatology. Vol. 70. 111 River St, Hoboken 07030-5774, Nj USA: Wiley, 2018.
Disclosure of Interests: None declared

DOI: 10.1136/annrheumdis-2019-eular.6957

\section{AB1371-HPR EFFECTS OF MORNING STIFFNESS ON THE PSYCHOSOCIAL AND FUNCTIONAL STATUS OF PATIENTS WITH JUVENILE IDIOPATHIC ARTHRITIS}

Fatma Birgül Kumbaroğlu' ${ }^{1}$, Aykut Özçadırcı ${ }^{1}$, Selcan Demir ${ }^{2}$, Yelda Bilginer ${ }^{2}$ Edibe Ünal', Seza Özen ${ }^{2}{ }^{1}$ Hacettepe University Faculty of Physical Therapy and Rehabilitation, Ankara, Turkey; ${ }^{2}$ Hacettepe University Faculty of Medicine, Department of Pediatric Rheumatology, Ankara, Turkey

Background: Juvenile Idiopathic Arthritis (JIA) is a chronic childhood autoimmune disease that has significant implications on a child's physical health and psychosocial integration (1). Common symptoms of JIA include pain, joint stiffness, joint swelling, fatigue, and decreased physical function $(2,3)$.

Objectives: The aim of this study is to investigate the effects of morning stiffness on the psychosocial and functional status of patients with JIA.

Methods: $387 \mathrm{JIA}$ patients were included in this study. To determine the functional status of the patients' functional subscale of The Juvenile Arthritis Biopsychosocial-Questionnaire (JAB-Q) and Childhood Health Assessment Questionnaire (CHAQ) were used. Psychosocial subscale of JAB-Q was used to assess psychosocial status. Finally, morning stiffness was measured as "less than 30 minutes", "between 30 minutes and 1 hour" and "more than 1 hour".

Results: A total of 162 boys and 225 girls participated in the study (Table 1). The effect of morning stiffness on functional and psychosocial status was examined with Kruskal Wallis analysis. There were statistically significant differences between the functional status (CHAQ Total, $p=0,001$; CHAQ General VAS, $p=0.012$; CHAQ Pain VAS, 0.001; Function JAB-Q, $\quad p<0.001$ ) of the patients and the duration of morning stiffness. However, there was no significant difference between the duration of morning stiffness and psychosocial status. Mann-Whitney $U$ test was performed to test the significance of a pairwise difference using Bonferroni correction to adjust for multiple comparisons revealed that the difference between the groups was due to the morning stiffness duration "less than 30 minutes" group (Table 2).

Abstract AB1371HPR Table 1. Descriptive statistics

\begin{tabular}{lc}
\hline & Mean \pm SD \\
\hline Age & $12.50 \pm 3.67$ \\
BMI & $19.93 \pm 4.34$ \\
Gender & \\
Female $[\mathrm{n}(\%)]$ & $225(58.14)$ \\
Male $[\mathrm{n}(\%)]$ & $162(41.86)$ \\
\hline
\end{tabular}

Abstract AB1371HPR Table 2. Mann-Whitney U test

\begin{tabular}{lcccc}
\hline & $\mathrm{p}$ & $\mathrm{p}$ & $\mathrm{p}$ & $\mathrm{p}$ \\
\cline { 2 - 5 } & $\begin{array}{c}\text { CHAQ } \\
\text { Total }\end{array}$ & $\begin{array}{c}\text { CHAQ (General } \\
\text { VAS) }\end{array}$ & $\begin{array}{c}\text { CHAQ (Pain } \\
\text { VAS) }\end{array}$ & Function \\
\hline $1-$ & $\mathbf{0 . 0 0 4}$ & $\mathbf{0 . 0 0 3}$ & $\mathbf{0 . 0 0 1}$ & $\mathbf{0 . 0 0 2}$ \\
2 & & 0.237 & 0.028 & $<0.001$ \\
$1-$ & $\mathbf{0 . 0 0 4}$ & & & 0.038 \\
3 & & 0.517 & 0.943 & \\
$2-$ & 0.393 & & &
\end{tabular}

$1=<30$ min morning stiffness, $2=30$ min- 1 hour morning stiffness, $3=>1$ hour morning stiffness

Conclusion: In our study, as a result psychosocial status was not affected by duration of morning stiffness. On the other hand, functionality of patients were getting worse as the duration of morning stiffness increases. It was concluded that psychosocial status should be dealt with independently of functional status, and children should be supported to participate in psychosocial environment such as school attendance, social activities.

\section{REFERENCES}

[1] Cassidy JT, Petty RE. Chronic arthritis in childhood. In Textbook of pediatric rheumatology. 5th edition. Edited by Cassidy JT, Petty RE, Laxer RM, Lindsley CB. Philadelphia, PA: Elsevier Saunders; 2005; 206-60

[2] Stanley LC, Ward-Smith P. The diagnosis and management of juvenile idiopathic arthritis. J Pediatr Health Care 2011;25:191-94. 
[3] Johnson CJ, Reilly KM, Murray KM. Etanercept in juvenile rheumatoid arthritis. Annals of Pharmacotherapy 2001;35:464-71.

Disclosure of Interests: None declared

DOI: 10.1136/annrheumdis-2019-eular.7316

\section{AB1372-HPR THE INVESTIGATION OF THE RELATIONSHIP BETWEEN PSYCHOSOCIAL STATUS OF CHILDREN WITH JIA AND PARENTS}

Aykut Özçadırcı ${ }^{1}$, Aybüke Seven ${ }^{1}$, Gamze Arın ${ }^{1}$, Yasemin Özel Aslıyüce ${ }^{1}$, Fatma Birgül Kumbaroğlu' ${ }^{1}$, Nur Banu Karaca', Selcan Demir ${ }^{2}$, Yelda Bilginer ${ }^{2}$, Edibe Ünal ${ }^{1}$, Seza Özen ${ }^{2} .{ }^{1}$ Hacettepe University Faculty of Physical Therapy and Rehabilitation, Ankara, Turkey, ${ }^{2}$ Hacettepe Universiy Faculty of Medicine, Department of Pediatric Rheumatology, Ankara, Turkey

Background: Juvenile idiopathic arthritis (JIA) is a heterogeneous group of diseases characterized by unknown origin arthritis that begins before the age of 16 years (1). Therefore, families are often affected by the disease of children. Parents and children often disagree with assessing different aspects of disease activity in JIA (2).

Objectives: The aim of this study is to investigate the relationship between children with JIA and their parents' psychosocial status.

Methods: A total of 345 children with JIA and their parents were included in the study $(n=690)$. Juvenile Arthritis Biopsychosocial Questionnaire (JAB-Q) was administered to the subjects (3). The psychosocial status of the individuals was evaluated by this questionnaires.

Results: The mean age of children included in the study $(n=345)$ was $12.32 \pm 3.76$ years. While the median value of the Child Psychosocial score was 10 (min: 0 max: 38 ), the median value of the Parent Psychosocial score was 6 (min: 0 max: 20). Correlation coefficients and statistical significance were calculated by using the Pearson test. A positive low correlation was found between the psychosocial status of the child and parents $(r=0.273, p<0.001)$ (Table 1).

Table 1. Correlations

\begin{tabular}{|c|c|c|c|c|}
\hline \multirow{6}{*}{$\begin{array}{l}\text { JAB- } \\
Q\end{array}$} & \multirow{3}{*}{$\begin{array}{c}\text { Child } \\
\text { Psychosocial }\end{array}$} & $r$ & 1,00 & 0,283 \\
\hline & & $p$ & & 0,000 \\
\hline & & $\mathrm{n}$ & 345 & 345 \\
\hline & \multirow{3}{*}{$\begin{array}{l}\text { Parents } \\
\text { Psychosocial }\end{array}$} & $r$ & 0,283 & 1,00 \\
\hline & & $\bar{p}$ & 0,000 & \\
\hline & & $\bar{n}$ & 345 & 345 \\
\hline
\end{tabular}

Conclusion: It was observed that there was a low relationship between the psychosocial status of children and parents. It was concluded that child and parents psychosocial status may be affected by other variables such as high disease activity, school attendance. Further studies are needed in this area including different variables and interaction psychosocial status.

\section{REFERENCES}

[1] Prakken, B., Albani, S., \& Martini, A. (2011). Juvenile idiopathic arthritis. The Lancet, 377(9783), 2138-2149.

[2] Garcia-Munitis P, Bandeira M, Pistorio A, Magni-Manzoni S, Ruperto N, Schivo A, et al. Level of agreement between children, parents, and physicians in rating pain intensity in juvenile idiopathic arthritis. Arthritis Rheum 2006;55:177-83.

Disclosure of Interests: None declared

DOI: 10.1136/annrheumdis-2019-eular.7319 AB1373-HPR

\section{AB1373-HPR BIOPSYCHOSOCIAL CHARACTERISTICS OF INPATIENTS, OUTPATIENTS AND PATIENTS WHO ATTEND A GROUP EXERCISE SESSIONS REGULARLY}

Yasemin Özel Aslıyüce, Aykut Özçadırc ${ }^{2}$, Gamze Arın ${ }^{3}$, Aybüke Seven ${ }^{3}$, Nur Banu Karaca ${ }^{4}$, Fatma Birgül Kumbaroğlu ${ }^{3}$, Edibe Ünal ${ }^{3}$, Şule Apraș Bilgen ${ }^{2}$. ${ }^{1}$ Institution of Health Sciences, Ankara, Turkey; ${ }^{2}$ Institution of Health Sciences, Ankara, Turkey; ${ }^{3}$ Institution of Health Science, Ankara, Turkey; ${ }^{4}$ Institution of Health Science, Ankara, Turkey

Background: Studies show that patients' biopsychosocial characteristics may be affected by various factors such as inpatient, outpatients, exercise intervention regularly. [1]. No studies have been found to examine this situation in the literature.
Objectives: The aim of this study was to investigate the biopsychosocial characteristics of patients with rheumatic diseases who were inpatients, outpatients and participated in an exercise intervention regularly.

Methods: A total of 105 patients were included in the study (inpatient, outpatient exercise intervention) (Table 1). For exercise intervention group, BETY as a biopsychosocial exercise model was applied 3 days a week for 3 months [2]. Biopsychosocial characteristics of the patients included in the study were evaluated by BETY- Biopsychosocial Questionnaire (BETY-BQ) [3]. In addition to the total score of $B E T Y-B Q$, the same time pain, functionality and fatigue, sexuality, emotional status and socialization subcategory of this questionnaire were evaluated on item basis among each patients.

Results: The demographics variables and BETY-BQ scores of the patients were shown in Table 1. There were a statistically significant differences among three groups. After post-hoc analysis, it was determined that there is no difference between the BETY-BQ scores of the outpatients and inpatients $(p>0.05)$, whereas the BETY-BQ scores of the patients who participated in the group exercise were lower $(p 0.05)$. When the items were analyzed, it was found that pain (items $2,3,5$, and 12), functionality and fatigue (items $6,7,11,26$, and 28), emotional status (items 16 and 17), and sleep (item 30) subcategory scores were also lower in patients who participated in BETY programme ( $\mathrm{p} 0.05)$.

Abstract Table 1. Demographic statistics and BETY-BQ scores

\begin{tabular}{|c|c|c|c|c|c|c|c|}
\hline & & \multicolumn{2}{|c|}{$\begin{array}{c}\text { Inpatient } \\
(\mathrm{n}=30)\end{array}$} & \multicolumn{2}{|c|}{$\begin{array}{l}\text { Outpatıent } \\
\qquad(n=44)\end{array}$} & \multicolumn{2}{|c|}{$\begin{array}{c}\text { Exercıse intervention } \\
\text { (BETY) } \\
(\mathrm{n}=\mathbf{3 1})\end{array}$} \\
\hline & & Female & Male & Female & Male & Female & Male \\
\hline \multirow[t]{2}{*}{ Gender (\%) } & & 61.3 & 37.8 & 87.2 & 12.8 & 53.7 & 7.4 \\
\hline & & \multicolumn{2}{|c|}{ XSD } & \multicolumn{2}{|c|}{ XSD } & \multicolumn{2}{|c|}{ XSD } \\
\hline Age (year) & & \multicolumn{2}{|c|}{46.3514 .56} & \multicolumn{2}{|c|}{46.0613 .26} & \multicolumn{2}{|c|}{48.6711 .89} \\
\hline BMI $\left(\mathrm{kg} / \mathrm{m}^{2)}\right.$ & & \multicolumn{2}{|c|}{24.195 .17} & \multicolumn{2}{|c|}{28.9818 .85} & \multicolumn{2}{|c|}{26.943 .84} \\
\hline \multirow[t]{2}{*}{ BETY-BQ (0-120) } & $p$ & \multicolumn{2}{|c|}{ XSD } & \multicolumn{2}{|c|}{ XSD } & \multicolumn{2}{|c|}{ XSD } \\
\hline & 0.027 & \multicolumn{2}{|c|}{49.1017 .94} & \multicolumn{2}{|c|}{45.6427 .93} & \multicolumn{2}{|c|}{33.8121 .73} \\
\hline
\end{tabular}

Conclusion: It is surprising that the biopsychosocial characteristics of the inpatients and outpatients were similar. According to this result, inpatients shouldnt be thought as worse than outpatients. On the other hand, the patients who participated in exercise intervention were improved in terms of biopsychosocial aspects. The positive effects of the BETY program on the biopsychosocial status of individuals have been demonstrated formerly [4]. It was concluded that inpatients should be supported to exercise in terms of their biopsychosocial needs during hospitalization period as well as rheumatic outpatients need.

\section{REFERENCES}

[1] Saketkoo, L.A. and J.D. Pauling, Qualitative methods to advance care, diagnosis, and therapy in rheumatic diseases. Rheumatic Disease Clinics of North America, 2018.

[2] Kisacik, P., et al., Investigating the effects of a multidimensional exercise program on symptoms and antiinflammatory status in female patients with ankylosing spondylitis. Complement Ther Clin Pract, 2016. 22: p. 38-43.

[3] NAL, E., et al., Romatizmalı hastalar iin bir yaşam kalitesi leğinin geliştirilmesi: madde havuzunun olussturulması. Journal of Exercise Therapy and Rehabilitation, 2017. 4(2): p. 67-75.

[4] Unal, E., et al. Effectiveness of a Biopsychosocial Exercise Approach in Rheumatic Diseases. in ARTHRITIS \& RHEUMATOLOGY. 2018. WILEY 111 RIVER ST, HOBOKEN 07030-5774, NJ USA.

Disclosure of Interests: None declared

DOI: 10.1136/annrheumdis-2019-eular.7221

\section{AB1374-HPR THE EFFECTIVENESS OF BIOPSYCHOSOCIAL EXERCISE PROGRAM ON PAIN COPING IN PATIENTS WITH ANKYLOSING SPONDYLITIS AND FIBROMYALGIA}

Aybüke Seven ${ }^{1}$, Aykut Özçadırcı' ${ }^{1}$, Gamze Arın ${ }^{1}$, Fatma Birgül Kumbaroğlư ${ }^{1}$, Nur Banu Karaca ${ }^{1}$, Ali Akdoğan ${ }^{2}$, Edibe Ünal ${ }^{1} .{ }^{1}$ Hacettepe University Faculty of Physical Therapy, Ankara, Turkey, ${ }^{2}$ Hacettepe University Faculty of Medicine, Department of Rheumatology, Ankara, Turkey

Background: Ankylosing spondylitis (AS) and fibromyalgia (FM) are rheumatic diseases with a high incidence in the community. Although many studies have been done on pain in these patient groups, the studies on coping with pain are very limited $(1,2)$. Bilişsel Egzersiz Terapi Yaklaşımı (BETY) is an exercise approach that developed in rheumatic patients. This approach has its own Biopsychosocial Questionnaire 